- New York University Medical Center, New York, NY (Josiane LaJoie, MD)

- Massachusetts General Hospital, Boston, MA (Elizabeth Thiele, MD, PhD)

- Children's National Medical Center, Fairfax, VA (William McClintock, MD)

- University of Chicago, Chicago, IL (Michael Kohrman, MD)

- Oakland Children’s Hospital, Oakland, CA (Candida Brown, MD)

- UCLA Medical Center, Los Angeles, CA (Joyce T $\mathrm{Wu}, \mathrm{MD}$ )

- University of Texas, Houston (Hope Northrup, $\mathrm{MD)}$
- University of Alabama, Birmingham (E Martina Bebin, MD, MPA and Bruce Korf, MD, PhD)

- The Cleveland Clinic Foundation, Cleveland, $\mathrm{OH}$ (Ajay Gupta, MD)

- University of Colorado, Denver (Paul Levisohn, MD \& Susan Koh, MD)

- Miami Children’s Hospital, Miami, FL (Ian O’Neil Miller, MD and Michael Duchowny, MD)

- Loma Linda University Medical Center, Loma Linda, CA (Stephen Ashwal, MD)

- UZ Brussels Hospital, Brussels, Belgium (Anna C Jansen, MD, PhD)

- Pennsylvania Medical Center, Philadelphia, PA (Peter Crino, MD, PhD and Katherine Nathanson, MD)

\title{
Hierarchical temporal processing deficit model of reality distortion and psychoses
}

\author{
RR Krishnan, M Fivaz, MS Kraus and RSE Keefe
}

Molecular Psychiatry (2012) 17, 470; doi:10.1038/mp.2011.54

Correction to: Molecular Psychiatry (2011) 16, 129-144; doi:10.1038/mp.2010.63

Following the publication of this article, the authors noted that the funding information was incomplete.
It should be noted that Drs Richard Keefe and Michael Kraus received support for this work from the Translational and Clinical Research (TCR) Programme funding from the Singapore National Research Foundation to the Institute of Mental Health, Singapore.

\section{Converging evidence for central 5-HT effects in acute tryptophan depletion}

MJ Crockett, L Clark, JP Roiser, OJ Robinson, R Cools, HW Chase, H den Ouden, A Apergis-Schoute, D Campbell-Meiklejohn, B Seymour, BJ Sahakian, RD Rogers and TW Robbins

Molecular Psychiatry (2012) 17, 470; doi:10.1038/mp.2011.134

Correction to: Molecular Psychiatry (2012) 17, 121-123; doi:10.1038/mp.2011.106; published online 30 August 2011
Following the online publication of this article, the authors noted that Dr Campbell-Meiklejohn's name was misspelled. The complete and correct author names appear above. 